\title{
The National Library of Norway, Oslo Division: Is it Possible to Make a 1913-Building Accessible for the Library User of 2005?
}

by SISSEL NILSEN

National Libraries are mostly regarded as important national institutions, but very few people outside the school and academic circles believe that there can be anything of interest for them inside such an institution.

In Norway we want the National Library to become more recognized - that is a challenge for all employees. We want to change the image and convince the Norwegian public that a national library is not a museum for dusty old books - but a modern and active library. We want to promote our collections in new ways - and thus raise the awareness of what services a national library can offer to the people.

We will also act as a link between the different types of libraries and serve as a excellence centre for interlending, bibliographic services, cataloguing and classification, reference work within our special fields, digitalising, preservation and book research.

Physical surroundings are not irrelevant to the way modern libraries want to present themselves. The restoration of the old building in Oslo will hopefully make it easier for the National Library, Oslo Division, to present our national heritage to the public. We consider openness as a keyword and transparency has been an aim for the preliminary planning and projecting for new underground stack-rooms and restoration of the old building. That's really a challenge.

Let me very briefly go through the somewhat strange history and development of the National Library of Norway: 
1815 Founded as a combined University and National Library of Norway in Oslo. Until the last world war Oslo had the only university in Norway.

1815 Legal deposit act decided that legal deposit copies printed in Norway should be delivered in Oslo instead of Copenhagen. Most of the Norwegian authors, however, still published their books in Copenhagen in the 20th century.

1905 Norway independent nation - separated from Sweden. Until the Napoleonic war Norway had been united with Denmark for 400 years.

1913 New National University Library building opened - intended to be large enough for 200 years acquisition.

1933 West wing added to the building.

1946 East wing added to the building.

1960 Great need for further extensions. The library had to rent area outside the building.

1980-ties Several reports suggesting a future independent National Library separated from the University of Oslo Library.

1985/86 Plans for extention of the 1913-building.

1989 New Legal Deposit act covering all types of media approved by Parliament.

1990 Establishment of the Rana Division of the National Library of Norway (connected directly to the Ministry of Culture) as a Deposit Library for all archival material from 1990 onwards. A second copy for public use should from now on be sent to the University of Oslo Library (today the National Library of Norway, Oslo Division).

1992 Establishment of the National Librarians office in Oslo was approved by the Parliament in order to coordinate National Library activities. At the same time the Parliament decided that the University of Oslo Library should be divided into two libraries: one for National Library functions and one for University Library functions. The national Library functions would remain in the old library building from 1913 situated in centre of Oslo.

$1994 \quad$ National Librarian was appointed. 
1997 Committee for planning restoration and extension of the 1913building is established.

1998 Director for the National Library, Oslo Division was appointed.

1999 The University of Oslo Library moves into the new library at the Oslo University campus.

1999 The National Library of Norway is fully established.

Since 1815 the library has been responsible for collecting and preserving all documents printed in Norway as well as documents relating to Norway Norwegea Extranea. The library has all archival copies up till 1990. From 1990 onwards the Rana Division keeps the archival copy, while the second copies of the legal deposits, as mentioned, are sent to the Oslo division for the public use.

When separated from the University library the Oslo Division also kept most of the special collections such as: Music and Sound, Manuscripts and Letters, Maps, Photos and Prints, Theatre, Posters, Leaflets, Norwegian American Emigrant material, Material on the Second world war, and special collections on the authors Ibsen and Bjørnson.

The Oslo Division also has the responsibility for making the National bibliography, keeping the Union Catalogue that gives Internet access to collections in 400 libraries in Norway as well as the Nordic Union Catalogue for periodicals. More than 60 databases are offered through Internet services.

In order to give the users the best possible service we need more space and a total renovation of the building that has been neglected by the University for many years and is unsuitable for modern library purposes. Ventilation is nonexistent. Only a room of ca $300 \mathrm{~m}^{2}$ has a proper ventilation and a security system, but here are kept only the most precious books and prints.

The old plan for a further extension of the building was now abandoned by the Ministry of Culture, and instead it is determined to build new underground stack-rooms in the park behind the building connected to the old library by a culvert. When the stacks are finished and the collections moved, the old building will be totally renovated. The idea of this project is to keep the material and the people apart - they need different temperature. We plan a simple mechanic transportation system for the books. 
The total cost of the new stacks $\left(9,000 \mathrm{~m}^{2}\right.$ net) and the total renovation of the old building was estimated to 400 millions NOK (1998) - furniture excluded. Although the project has developed slower than we anticipated, we are pleased that in a recent report to the Parliament on Archives, Library and Museums the Government now has the rebuilding of the National Library as the highest priority. Some months after this report was sent to the Parliament, we got a new government, but they have announced that they will not withdraw the report, so we are almost certain that the money for building will be in the next State-budget. The money for finishing the initial project is granted this year.

Still there is one negative factor that worries us. In order to reduce the costs at the moment, the Ministry of Culture has proposed to reduce the size of the stacks from $10,750 \mathrm{~m}^{2}$ gross to $4,000 \mathrm{~m}^{2}$ gross and extend the underground stacks later. This means we will not have enough room for the collections when the project is finished and might have to rent extra space outside the library for parts of the collection. That will mean that the accessibility to parts of the collections will be worse than today. Our hope is that the Parliament when making their decision later this year will decide that the verified size for the stacks is to be built all at the same time. The Parliament Committee for Culture is well informed about this problem.

While informing in more detail about our plans for the renovation I will keep to the preliminary project plans that will contribute to give the old building a much better infrastructure in order to make the collections more accessible to users of 2005.

The present building has a total of $23,133 \mathrm{~m}^{2}$ gross, 14,369 net of which $8,295 \mathrm{~m}^{2}$ have floor with low headroom, $2,851 \mathrm{~m}^{2}$ with normal headroom and $3,223 \mathrm{~m}^{2}$ with high headroom. After refurbishment, according to the present plan some of the floors with low headroom have to be removed, and this area will then be reduced to about $10,000 \mathrm{~m}^{2}$ net. In addition we need stack-rooms with an area of $9,000 \mathrm{~m}^{2}$ net which will be sufficient for 30 years acquisition. Today there is an annual acquisition of 1,200 linear metres.

\section{GROUND FLOOR}

Both the exterior of the building and parts of the interior are protected and cannot be changed, but in spite of this, we will endeavour to make the visitors feel welcome immediately when entering the building. Parts of the original 
reception area with the high ceiling and large heavy staircase leading to the other floors are being kept as it is. This is quite impressing and the frescos in the ceiling and on the walls of the staircase are unique.

We plan to gather the rooms for cultural activities on the ground floor, so that the rest of the library can be closed off when evening arrangements are going on.

The present auditorium „The Royal Library“ - named so because the collection in the room was a gift from the Swedish King in 1905 - will be preserved more or less as it is today, and will function as a seminar/meeting room for up to 100 people.

There will also be a new auditorium - a multi-purpose room for up to 200 people and an exhibition area. The exhibitions will also be mounted on our website like we have done with all our exhibitions since 1999.

The ground floor will also have a cafeteria.

We want easier access for the user to the special collections. These are very sheltered today, it is quite difficult for the visitor to use the different type of material of great research value.

The special collections will be placed in the two wings of the ground floor and the floor below (minus 2). Manuscripts, maps, photos etc. will be placed in the east wing with a direct access to the culvert and the underground stacks. The Music and Sound Department, which is also Norway's most important music library and have big foreign collections as well as all the Norwegian material, will be in the west wing with access to nearby stacks on the floor below. The special collections are now building up reference collection on open shelves in their reading-rooms. Up till now the library has, except for the Music Department, only had one general reference collection in the main reading room.

When grouping the special collections like this we hope to extend the opening hours for the special collections. The staff, although being specialists within their own field, can work more as a team.

The entrance area will also provide cluster of terminals for internet use for drop-ins, library cards will be issued here and a security system based on radio transmission will be placed at the doorstep. This system is brand new in Europe, and we are in the process of installing it to secure our Ibsen- 
collection which will be moved this summer to the Centre for Ibsen studies in a University building close to the library.

\section{RD FLOOR}

The third floor will be the other main floor for the public. On this floor we have to keep most of the rooms as they are due to preservation reasons. This floor will give the visitors the main access to the National and Nordic Collections of which most will be kept in the closed underground stacks. The archival copies can only be used in the reading room.

The old main reading room is being kept as it is, but refurnished and equipped so that laptops can be used at all seats.

Today we have three service points: reading room, enquiry desk and circulation desk. This is too expensive and not very efficient. We plan one joint counter where the staff can work as a team.

We have planned one computer area and hope to get rid of most of the card catalogue that occupy large area today. We have applied to the Ministry of Culture for project money for a period of four years to converting the main catalogue. Next year we will have finished converting the National bibliography back to 1931 , but still more than 400,000 books need to be converted into the online catalogue.

There will also be room for an area for microfilm and a nearby stack-room for self service. These machines are heavily used every day. We also need researcher rooms for transmitting digital material from the digital archives in the Rana Division, such as broadcasting programmes, films, archival electronic material etc. Copyright regulations might not allow us to transmit the material directly to the user or the local library. It is a paradox that the more easy it is technically to give access to new material, the more restrictions the owner seems to put on it.

The library also intends to have all the Norwegian newspapers and a selection of the periodicals on open shelves, and we are also considering to have parts of the most recent Norwegian collection on open shelves for instance for three years. 
The library plans to act as a centre for the Norwegian literature - whether on print or published in other forms and to promote books and reading. As Norwegian is a minor language it is especially important to promote the national literature.

Norway is a very long country with long distances and the National Library feels that it is very important to digitalise a lot of the material in order to promote it to the whole country, thus enabling the researchers to study at their own desk. This means that we have to put lots of efforts in the coming years in digitalising much of our material. We will have to hunt for sponsors in order to make this possible.

The other floors of the building will mainly consist of offices for the staff and technical rooms.

The time schedule for the project:

\begin{tabular}{|l|l|}
\hline Winter 2000/2001 & Building the underground stack-rooms starts \\
\hline 2002 & Stacks finish \\
\hline Winter 2002/2003 & $\begin{array}{l}\text { Move collection } \\
\text { The public will from then on be served from rented } \\
\text { premises in the building opposite the library, but } \\
\text { most of the staff will move to rented areas elsewhere } \\
\text { in the city. }\end{array}$ \\
\hline 2003/ 2004 & Renovation of the old building \\
\hline Spring 2005 & Open renovated building \\
\hline
\end{tabular}

We do hope to make the new renovated library a better and more exciting library for the visitors, the researchers, for the staff and for the Norwegian public as a whole. We will endeavour to improve the service so that the users will not have to wait more than 30 - 50 minutes to have the wanted material in hand (today they often have to wait until the next day). We will promote the collections, making exciting exhibitions and literary and music programmes so that everybody feels there is something of interest for them. 
SISSEL NILSEN

Sissel Nilsen

Najonalbiblioteket avd Oslo

PB 2674 Solli

0203 Oslo, Norway

sissel.nilsen@nb.no 